Article

\title{
Nanoscale graphene oxide sheets as highly efficient carbocatalysts in green oxidation of benzylic alcohols and aromatic aldehydes
}

\author{
Alireza Sedrpoushan a,*, Masoud Heidari a, Omid Akhavan b,c \\ a Department of Chemical Technologies, Iranian Research Organization for Science and Technology (IROST), P.0. Box 33535-111, Tehran, Iran \\ b Department of Physics, Sharif University of Technology, P.O. Box 11155-9161, Tehran, Iran \\ c Institute for Nanoscience and Nanotechnology, Sharif University of Technology, P.O. Box 14588-89694, Tehran, Iran
}

\section{A R T I C L E I N F 0}

\section{Article history:}

Received 19 November 2016

Accepted 22 December 2016

Published 5 April 2017

\section{Keywords:}

Carbocatalyst

Nanoscale graphene oxide

Green chemistry

Oxidation

Metal-free catalyst

Colloidal dispersion

\begin{abstract}
A B S T R A C T
Nanoscale graphene oxide (NGO) sheets were synthesized and used as carbocatalysts for effective oxidation of benzylic alcohols and aromatic aldehydes. For oxidation of alcohols in the presence of $\mathrm{H}_{2} \mathrm{O}_{2}$ at $80^{\circ} \mathrm{C}$, the NGOs (20\% mass fraction) as carbocatalysts showed selectivity toward aldehyde. The rate and yield of this reaction strongly depended on the nature of substituents on the alcohol. For 4-nitrobenzyl alcohol, $<10 \%$ of it was converted into the corresponding carboxylic acid after 24 h. By contrast, 4-methoxybenzyl alcohol and diphenylmethanol were completely converted into the corresponding carboxylic acid and ketone after only 9 and $3 \mathrm{~h}$, respectively. The conversion rates for oxidation of aromatic aldehydes by NGO carbocatalysts were higher than those for alcohol oxidation. For all the aldehydes, complete conversion to the corresponding carboxylic acids was achieved using $7 \%$ (mass fraction) of $\mathrm{NGO}$ at $70{ }^{\circ} \mathrm{C}$ within $2-3 \mathrm{~h}$. Possible mechanisms for NGO carbocatalyst structure-dependent oxidation of benzyl alcohols and structure-independent oxidation of aromatic aldehydes are discussed.
\end{abstract}

(C) 2017, Dalian Institute of Chemical Physics, Chinese Academy of Sciences. Published by Elsevier B.V. All rights reserved.

\section{Introduction}

Because of the mass production and utilization of various organic materials in the modern world, effective and green catalytic approaches are required to reduce the risks of these chemicals to humans and the environment [1-8]. The most widely explored catalytic nanomaterials are different forms of transition metals, such as metal oxides [9] and hybrid materials [10], which need ultraviolet (UV)-visible irradiation to work efficiently. However, these catalytic nanomaterials may induce toxic effects, and can also be complex to remove from the environment $[11,12]$. Consequently, recent research has focused on development of metal-free catalysts.

Recently, carbocatalysts have been proposed as promising metal-free alternatives to transition metal catalysts [13-16].
Different carbon allotropes have been investigated and used as carbocatalysts $[1,13,17-26]$. The various carbon allotropes have the same basic graphene-based structure [14,23,24], and in recent years, graphene-based materials have attracted attention as carbocatalysts. Graphene-based structures such as pure graphene, doped graphene, and graphene oxide (GO) have been used as carbocatalysts in various reactions, but the graphene-based carbocatalytic field is still in its infancy [1,18,27-29]. Because of its acidic nature, the most common uses of GO are in organic reactions such as Michael addition, Friedel-Crafts reaction, aza-Michael addition, and ring opening polymerization [30-38]. The first reported application of graphene as a carbocatalyst was of GO for the oxidation of benzyl alcohol [39]. Since then, applications of graphene and/or reduced GO (rGO) sheets to reduction of nitrobenzene [40], oxi-

\footnotetext{
* Corresponding author. E-mail: sedrpoushan1395@gmail.com

DOI: 10.1016/S1872-2067(17)62776-1 | http://www.sciencedirect.com/science/journal/18722067 | Chin. J. Catal., Vol. 38, No. 4, April 2017
} 
dation of 9H-fluorene [41], and oxidation of benzene to phenol [42] have been reported. Although graphene-based carbocatalysts are promising, they require harsh conditions, long reaction time, high catalyst concentrations, and produce low yields. Because defects in carbonaceous skeletons act as effective active sites for carbocatalysis [18,43,44], research on graphene-based carbocatalysts has concentrated on producing defects by adding heteroatoms such as boron, nitrogen, and sulfur $[1,18,45]$. These defective graphene structures have been widely used in oxidation reactions and produce higher yields than pure graphene or rGO [46-51]. However, synthesis of these structures is often complex, requiring doping reagents and specialized equipment, which makes their widespread application in catalysis difficult [18]. Therefore, more effective carbocatalysts need to be developed.

To date, no one has reported increasing the carbocatalytic activity of graphene sheets by decreasing the dimensions of the sheets. In addition, all previous reports on graphene-based materials have been for solvent free and/or heterogeneous catalytic systems. There have been no reports on the application of graphene-based materials as colloidal dispersion systems, that is, systems at the boundary between homogeneous and heterogeneous catalyst systems, to carbocatalysis. It is expected that a reduction in the size of GO will increase the peroxidase-like activity of the graphene skeleton. This is because any reduction in size will increase the density of defects, especially vacancies at edges, and it has been determined that lone pairs in the zigzag structure of $s p^{2}$ bonds at vacancies at edges, which have high delocalization states, are active sites for the peroxidase-like activity of carbonaceous structures [42,52-58]. It is important to retain oxygen functional groups of the graphenic sheets during any size reduction, because they contribute to the ability of nanoscale graphene oxide (NGO) to disperse in aqueous solutions and form a colloidal dispersion system. Both the method for decreasing the size of GO sheets and the magnitude of the size reduction could affect the catalytic performance of the NGO. It has been determined that sonication can provide energy for oxidative cleavage of the $\mathrm{C}-\mathrm{C}$ bond of $\mathrm{GO}$ sheets by $\mathrm{O}_{2}$ from air [59], but does not lead to physical breaking of the sheets. Moreover, in comparison with thermodynamic methods, sonication results in only partial cleavage at oxygen containing functional groups [60].

The aims of this work were to investigate reducing the dimensions of GO to NGO with minimum loss of oxygen functional groups, and to prepare a colloidal dispersion of a carbocatalysts for oxidation reactions. Because of the benefits of sonication discussed above, we used sonication for the synthesis NGO from GO. After physical and chemical characterization of $\mathrm{NGO}$, its ability to catalyze oxidation of benzylic alcohols was examined in an aqueous medium using $\mathrm{H}_{2} \mathrm{O}_{2}$ as an oxidant. Further information was obtained by applying the NGO catalyst to oxidation of aromatic aldehydes.

\section{Experimental}

\subsection{Preparation of NGO sheets}

A modified Hummers' method [61] coupled with a lengthy sonication step was used for synthesis of the NGO sheets, as reported in another study [62]. Briefly, $0.5 \mathrm{~g}$ of graphite and 0.5 $\mathrm{g}$ of $\mathrm{NaNO}_{3}$ were stirred in $23 \mathrm{~mL}$ of $\mathrm{H}_{2} \mathrm{SO}_{4}$ for $12 \mathrm{~h}$ at room temperature (RT). The mixture was then placed in an ice bath and $3 \mathrm{~g}$ of $\mathrm{KMnO}_{4}$ was slowly added with stirring for $2 \mathrm{~h}$. The temperature was then increased to $40{ }^{\circ} \mathrm{C}$ with stirring for $1 \mathrm{~h}$. Next, $40 \mathrm{~mL}$ of deionized (DI) water was added to the suspension, and temperature was increased to $90{ }^{\circ} \mathrm{C}$ and held at this temperature for $1 \mathrm{~h}$. Then, $100 \mathrm{~mL}$ of DI water was added, and after decreasing the temperature to $30{ }^{\circ} \mathrm{C}, 3 \mathrm{~mL}$ of $\mathrm{H}_{2} \mathrm{O}_{2}$ was added to the mixture. To remove sulfate and manganese ions, the reaction product was repeatedly washed with a $5 \%$ (volume fraction) $\mathrm{HCl}$ solution and DI water. The solid product was retained and $100 \mathrm{~mL}$ of DI water was added, followed by sonication for $8 \mathrm{~h}$. The mixture was then centrifuged at $5000 \mathrm{r} / \mathrm{min}$ for $10 \mathrm{~min}$, and the pellet was removed. The supernatant was retained and washed two more times with $100 \mathrm{~mL}$ of DI water followed by sonication for $8 \mathrm{~h}$. The second and third centrifugation steps were at $7000 \mathrm{rpm}$ (10 min) and $10000 \mathrm{rpm}$ (30 min), respectively. These washing steps separated out any large particles and/or clusters and the supernatant changed from a turbid brown solution to a clear brown solution, which was used in the carbocatalytic reactions.

\subsection{Oxidation of benzylic alcohols by $N G O$}

To study the catalytic effect of the NGO sheets on the oxidation of benzylic alcohols, we used $\mathrm{H}_{2} \mathrm{O}_{2}$ as an oxidant in an aqueous solution. Various mass fractions of the NGO sheets $((5-200) \%)$ and different reaction temperatures (RT to $100^{\circ} \mathrm{C}$ ) were investigated. In a preliminary experiment, benzyl alcohol was heated in the presence of $\mathrm{H}_{2} \mathrm{O}$ as solvent, an excess amount of $\mathrm{H}_{2} \mathrm{O}_{2}$ as oxidant, and $200 \%$ (mass fraction) of $\mathrm{NGO}$ as catalyst at $100{ }^{\circ} \mathrm{C}$ for $24 \mathrm{~h}$. To ensure that the only oxidant present was $\mathrm{H}_{2} \mathrm{O}_{2}$, the reaction was carried out under $\mathrm{N}_{2}$ atmosphere. To study the role of $\mathrm{H}_{2} \mathrm{O}_{2}$, the oxidation of benzyl alcohol was also conducted with different concentrations of $\mathrm{H}_{2} \mathrm{O}_{2}(10,2.2,1,0.5$ and 0 equivalents (eq.)) in the presence of $100 \%$ (mass fraction) NGO in $2 \mathrm{~mL}$ of DI water at $100{ }^{\circ} \mathrm{C}$ for $24 \mathrm{~h}$. To optimize the different reaction parameters, the effects on the yield were investigated for different benzyl alcohol derivatives (benzyl alcohol, and 4-chloro, 4-methoxy, and 4-nitro derivatives), NGO mass fractions $((10-200) \%)$ reaction temperatures (RT to 100 ${ }^{\circ} \mathrm{C}$ with (20-100)\% (mass fraction) of $\mathrm{NGO}$ and 2.2 eq. of $\mathrm{H}_{2} \mathrm{O}_{2}$ ), and reaction time (1-24 h with $20 \%$ (mass fraction) of NGO and 2.2 eq. of $\mathrm{H}_{2} \mathrm{O}_{2}$ at $80{ }^{\circ} \mathrm{C}$ ). The role of substituents on the benzylic carbon in the oxidation process was investigated by studying the oxidation of 1-phenylethanol and diphenylmethanol in the presence of $20 \%$ (mass fraction) of NGO and 1.1 eq. of $\mathrm{H}_{2} \mathrm{O}_{2}$ at $80^{\circ} \mathrm{C}$ for $24 \mathrm{~h}$. Finally, to highlight the catalytic performance of the $\mathrm{NGO}$, the oxidation reactions of all of the benzyl alcohol derivatives were conducted with $\mathrm{H}_{2} \mathrm{O}_{2}$ but without NGO at $100{ }^{\circ} \mathrm{C}$ for $24 \mathrm{~h}$. The progress of all reactions was monitored by thin layer chromatography (aluminum sheets, $20 \times 20 \mathrm{~cm}$, Merck Millipore) and gas chromatography (PHILIPS PU4500). After completion of the reaction the prod- 
uct was extracted into $\mathrm{CH}_{2} \mathrm{Cl}_{2}(3 \times 10 \mathrm{~mL})$.

\subsection{Oxidation of aromatic aldehydes by $N G O$}

The performance of NGO sheets as carbocatalysts was also investigated for the oxidation of aldehydes (benzaldehyde, and its 4-chloro, 4-hydroxy, and 4-nitro derivatives). To investigate the role of NGO in the oxidation of each benzaldehyde derivative to the corresponding carboxylic acid, the reaction was performed with $100 \%$ (mass fraction) of NGO in the absence of $\mathrm{H}_{2} \mathrm{O}_{2}$ at reaction temperatures ranging from RT to $100^{\circ} \mathrm{C}$ under the ambient atmosphere for $24 \mathrm{~h}$. Then, the reaction conditions were optimized as follows: concentration of NGO, $(0-100) \%$ (mass fraction) of $\mathrm{NGO}$ with 1.1 eq. of $\mathrm{H}_{2} \mathrm{O}_{2}$ at $80^{\circ} \mathrm{C}$ for $12 \mathrm{~h}$; reaction temperature, $7 \%$ (mass fraction) of NGO with 1.1 eq. of $\mathrm{H}_{2} \mathrm{O}_{2}$ at $\mathrm{RT}-80{ }^{\circ} \mathrm{C}$ for $12 \mathrm{~h}$; reaction time, $7 \%$ (mass fraction) of NGO with 1.1 eq. of $\mathrm{H}_{2} \mathrm{O}_{2}$ at $70^{\circ} \mathrm{C}$. All reactions were contin- uously monitored by thin layer chromatography and gas chromatography.

\subsection{The effect of oxidation conditions on the structure of NGO}

Because NGO is a carbonaceous structure and can undergo oxidation, the effects of the oxidation reaction conditions on the structure of NGO were studied. Fourier transform infrared spectroscopy (FTIR) and UV-visible spectroscopy were used to analyze structure of $\mathrm{NGO}$ after reaction with $\mathrm{H}_{2} \mathrm{O}_{2}$ at $80{ }^{\circ} \mathrm{C}$ for 8 h.

\subsection{Oxidation by similar catalysts}

To further understand the effects of various characteristics of the NGO catalysts on the oxidation reactions, some similar catalysts were also used and the results were compared. The
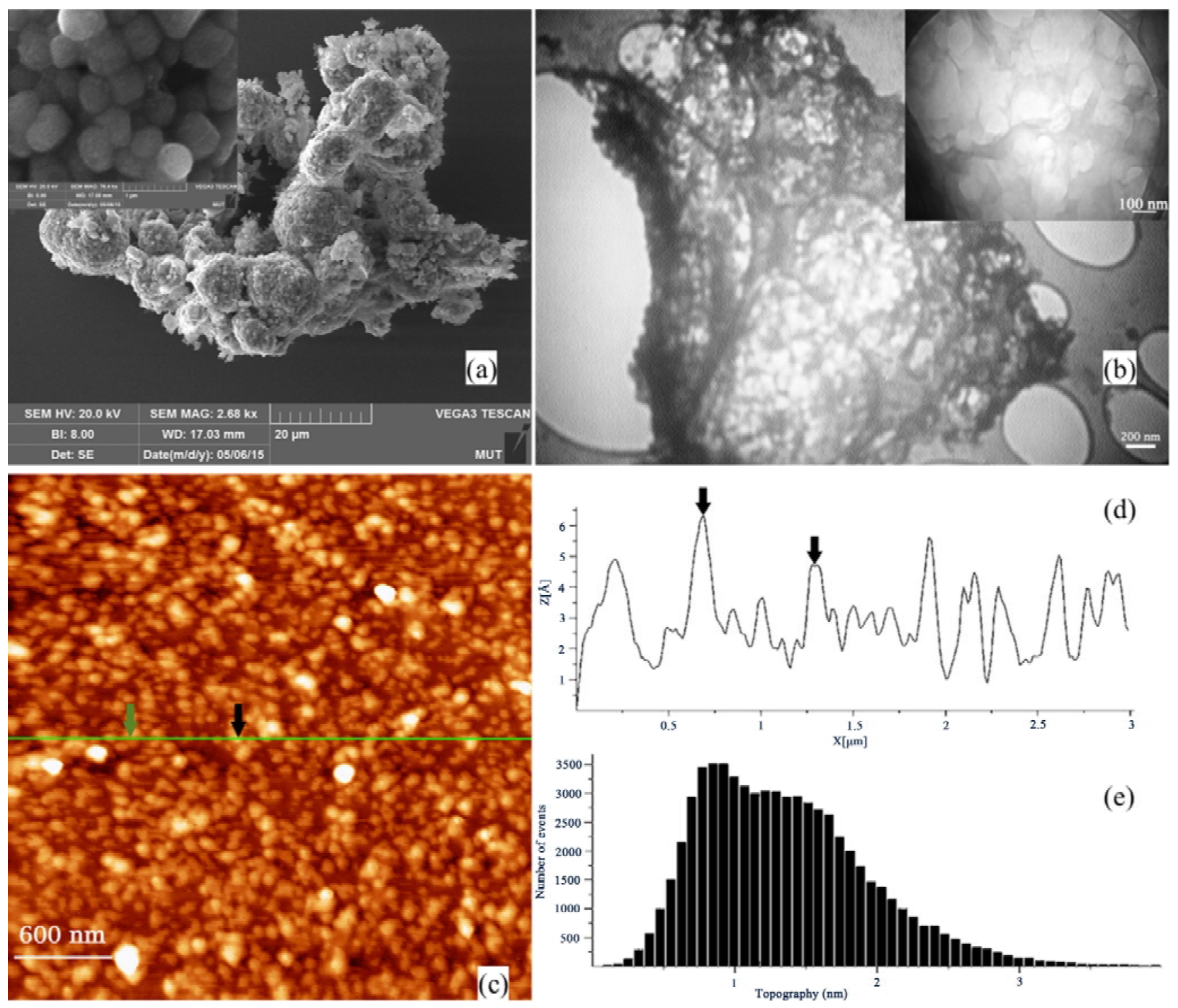

Fig. 1. (a) Scanning electron microscopy image of synthesized NGO clusters, and a magnification (inset); (b) transmission electron microscopy image of synthesized NGO sheets, and a magnification (inset); (c) atomic force microscopy image of the NGO structure; (d) height profile diagram of a line; (e height profile histogram of the atomic force microscopy image. 

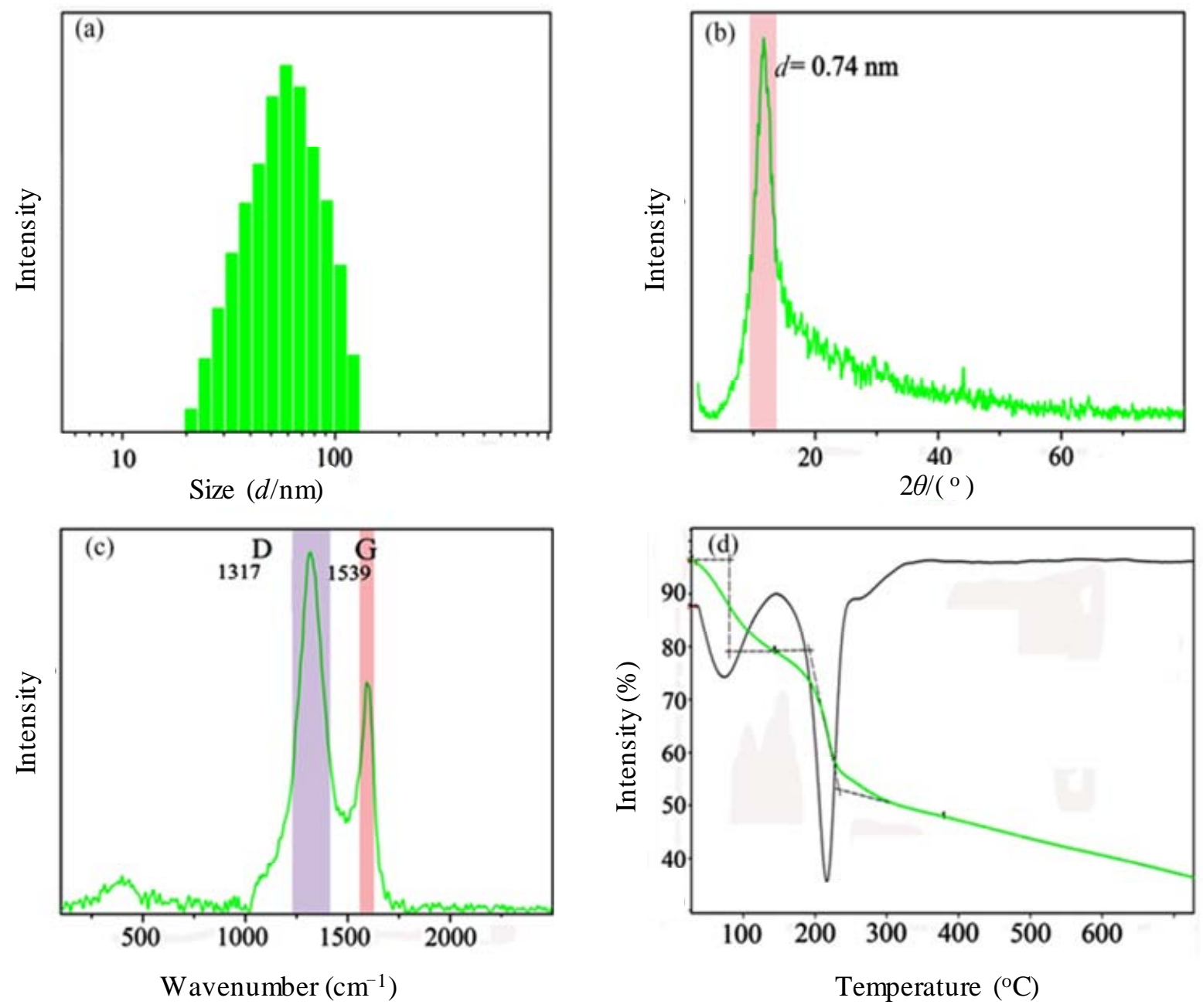

Fig. 2. (a) Dynamic light scattering histogram; (b) X-ray powder diffraction pattern; (c) Raman spectrum; (d) Thermogravimetric analysis/differential thermal analysis of NGO.

other catalysts were NGO-amide, acetic acid, benzoic acid, and epoxy cyclohexane. The oxidation reactions of benzyl alcohol and benzaldehyde were examined using 20\% (mass fraction) of each catalyst in the presence of $\mathrm{H}_{2} \mathrm{O}_{2}$ at $100{ }^{\circ} \mathrm{C}$ for $24 \mathrm{~h}$. NGO-amide was prepared by converting the carboxylic acid groups to amides by addition of aniline according to an established method [63]. Moreover, to study the oxidation of alcohols by peroxy acids, we used 1.8 eq. of meta-chloroperbenzoic acid (mCPBA) as an oxidant instead of $\mathrm{H}_{2} \mathrm{O}_{2}$ in the oxidation of benzyl alcohol. The reaction was also investigated by adding a stoichiometric amount of KI as a radical scavenger [64] to the reaction medium.

\section{Results}

\subsection{Characterization of NGO sheets}

The morphology, size, and size distribution of the NGO sheets were studied by scanning electron microscopy, transmission electron microscopy, atomic force microscopy, and dynamic light scattering (DLS) (Figs. 1 and 2). The scanning electron microscopy images showed highly porous NGO clus- ters (Fig. 1(a)). The formation of clusters could be assigned to aggregation of the NGO sheets in the following two stages: (1) initial aggregation of the NGO sheets, which gave particles with diameters of approximately $500 \mathrm{~nm}$, and (2) aggregation of the particles to form clusters with dimensions of approximately $100 \mu \mathrm{m}$. The transmission electron microscopy, atomic force microscopy, and DLS results showed these clusters could disintegrate into sheets with nanoscale dimensions under sonication. The sheets were less than $100 \mathrm{~nm}$ wide (Fig. 1(b) and (c)). The thickness of the sheets ( 1 nm, Fig. 1(d) and (e)) was consistent with the thickness of single-layer GO sheets $(\sim 0.8$ nm) [65-67]. The DLS histogram (Fig. 2(a)) showed that the average width of the NGO sheets was approximately $60 \mathrm{~nm}$.

The X-ray powder diffraction pattern of the NGO sheets (Fig. 2(b)) showed only one diffraction peak at $2 \theta=11.63^{\circ}$, which corresponded to a $d$-spacing of approximately $0.74 \mathrm{~nm}$ and was consistent with the typical thickness of GO sheets. There was no diffraction peak at $2 \theta=26.30^{\circ}$, which is characteristic of the $d$-spaceing of graphite $(\sim 0.34 \mathrm{~nm})$ [68], which indicated that effective oxidation of the starting graphitic materials had occurred.

The Raman spectrum of the NGO sheets (Fig. 2(c)) showed 

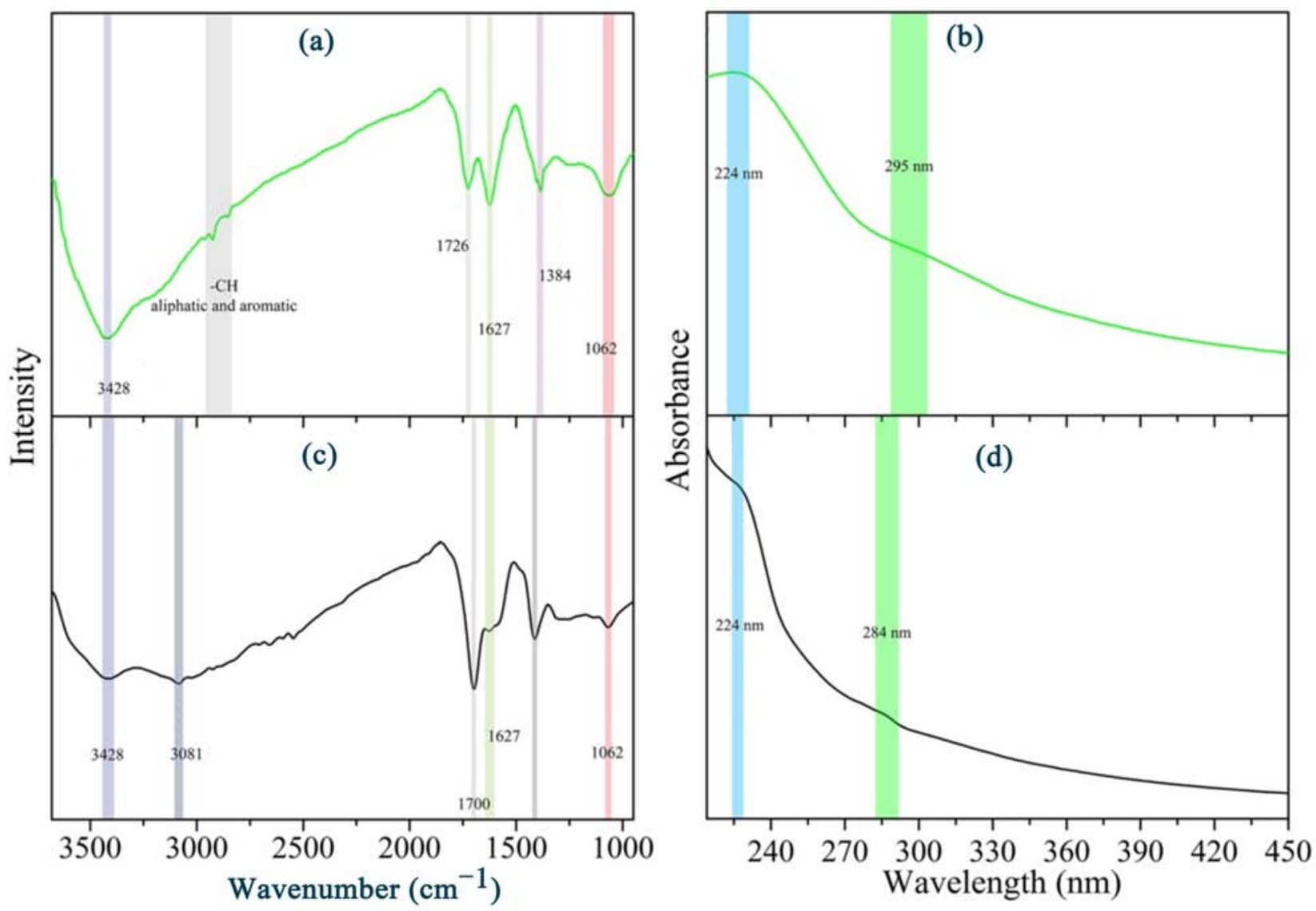

Fig. 3. (a) Fourier transform infrared (FTIR) spectrum of unreacted NGO; (b) Ultraviolet (UV)-visible spectrum of unreacted NGO; (c) FTIR spectrum of NGO after oxidation; (d) UV-visible spectrum of NGO after oxidation.

two bands for carbon at 1540 and $1317 \mathrm{~cm}^{-1}$ for the $\mathrm{G}$ and the D bands, respectively. In Raman spectroscopy, the $G$ band $\left(\sim 1580 \mathrm{~cm}^{-1}\right)$ results from $E_{2 \mathrm{~g}}$ phonon scattering from the graphitic structure and the D band $\left(\sim 1350 \mathrm{~cm}^{-1}\right)$ originates from the breathing mode of $\kappa$-point phonons of A $A_{1}$ symmetry of the $s p^{3}$ defect bonds $[69,70]$. The $\mathrm{D}$ band can also arise from amorphous carbon species, edge defects, grain boundaries, and vacancies in disordered carbonaceous structures [71]. The ratio of the intensities of these bands $\left(I_{G} / I_{D}\right)$ can be used to measure the $s p^{2}$ domain size of a carbon structure with both $s p^{2}$ and $s p^{3}$ bonds. In this work, the $I_{\mathrm{G}} / I_{\mathrm{D}}$ ratio was 0.637 , indicating the presence of a high level of disorder/defects in the NGO structure, which could act as active sites in catalytic reactions.

The thermogravimetric analysis/differential thermal analysis results of NGO samples under $\mathrm{N}_{2}$ (Fig. 2(d)) showed two major mass losses. The first mass loss stage was from 50 to 110 ${ }^{\circ} \mathrm{C}$ with a $21 \%$ mass reduction because of loss of water. The second mass loss stage was from 140 to $400{ }^{\circ} \mathrm{C}$ with a $31 \%$ mass reduction corresponding to loss of labile oxygen containing functional groups, particularly carboxylic acid groups, to form $\mathrm{CO}_{2}$ and $\mathrm{CO}$ gas $[59,60,72]$.

The molecular structure of the NGO sheets was further investigated by FTIR spectroscopy. The FTIR spectrum (Fig. 3(a)) exhibited the following characteristic peaks: $3428 \mathrm{~cm}^{-1}$ for $\mathrm{O}-\mathrm{H}$ stretching vibrations of phenols, alcohols, carboxylic acid, and adsorbed water; $1726 \mathrm{~cm}^{-1}$ for $\mathrm{C}=0$ stretching vibrations of carboxylic acid; $1627 \mathrm{~cm}^{-1}$ for $\mathrm{C}-\mathrm{C}$ stretching in-ring vibrations of benzene rings; $1384 \mathrm{~cm}^{-1}$ for $\mathrm{C}-\mathrm{C}$ stretching in-ring vibrations of benzene rings, $\mathrm{C}-\mathrm{H}$ bending and rocking of alkanes, and $\mathrm{O}-\mathrm{H}$ deformations in $\mathrm{C}-\mathrm{OH}$ groups; and $1062 \mathrm{~cm}^{-1}$ for $\mathrm{C}-\mathrm{O}$ stretching of alcohols, carboxylic acid, and ethers. These results confirmed the presence of a variety oxygen containing functional groups on the NGO sheets.

The UV-visible spectrum of the NGO sheets (Fig. 3(b)) showed an absorption peak at $224 \mathrm{~nm}$ for the $\pi \rightarrow \pi^{*}$ transition of $\mathrm{C}=\mathrm{C}$ bonds in the $s p^{2}$ domain of the carbon skeleton [73]. In addition, a shoulder at $295 \mathrm{~nm}$ was assigned to the $\mathrm{n} \rightarrow \pi^{*}$ transition of $\mathrm{C}=\mathrm{O}$ bonds [74]. It is worth noting that a photoluminescence peak was not detected for the NGO sheets with excitation at $330 \mathrm{~nm}$ at $\mathrm{pH}=7$. This is consistent with the nanoscale dimensions $(100 \mathrm{~nm})$ of the NGO sheets [75]. These results show that the NGO sheets do not behave as quantum dots.

To investigate if the NGO contained heavy metals, it was analyzed by inductively coupled plasma optical emission spectrometry. With a detection limit of $100 \mathrm{ppb}$, no heavy metals were detected in an aqueous suspension of the NGO.

\subsection{Oxidation of benzylic alcohols by the NGO carbocatalyst}

In oxidation of benzyl alcohol derivatives by the NGO catalyst, all of the alcohols were oxidized and the reaction did not stop at the aldehyde but proceeded to the carboxylic acid 
(a)

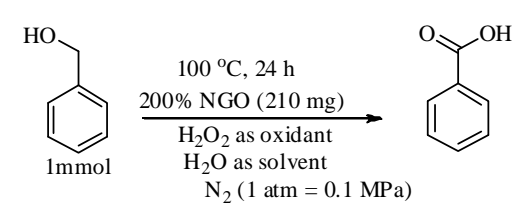

(c)

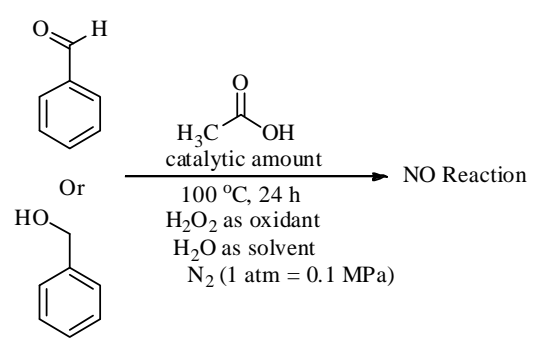

(e)

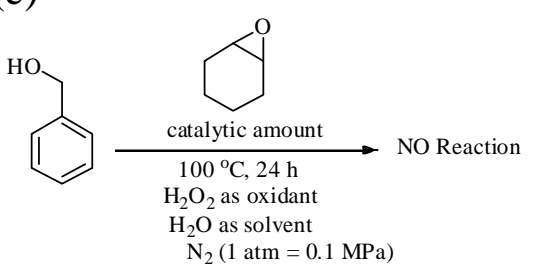

(b)

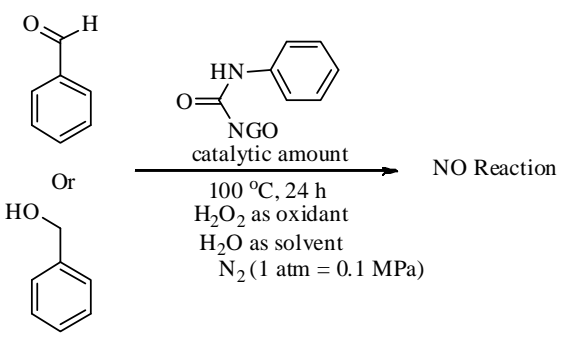

(d)

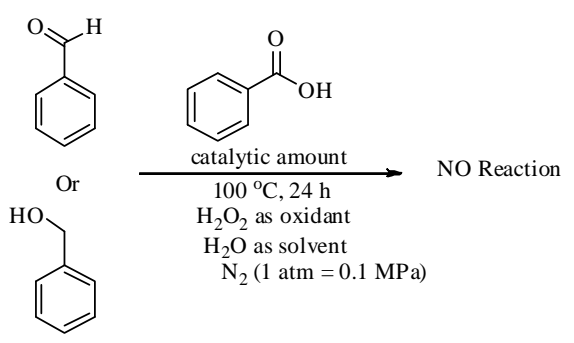

(f)

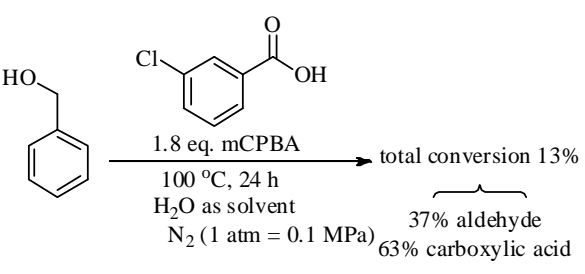

(g)

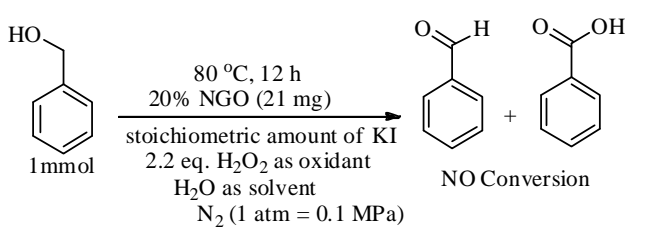

Scheme 1. Oxidation of benzyl alcohol and/or benzaldehyde in the presence of (a) NGO, (b) NGO-amide, (c) acetic acid, (d) benzoic acid, and (e) epoxy cyclohexane as catalysts, (f) meta-chloroperbenzoic acid (oxidant) and (g) KI (radical scavenger).

(Scheme 1(a)). Based on the reaction optimization experiments, the optimum conditions were 2.2 eq. of $\mathrm{H}_{2} \mathrm{O}_{2}$ (Table 1), $20 \%$ (mass fraction) of NGO (Table 2), and a reaction temperature of $80^{\circ} \mathrm{C}$ (Table 3). The low yield for oxidation of benzyl alcohols in the absence of NGO confirmed the NGO acted as a catalyst (Table 2). Altering the concentration of $\mathrm{H}_{2} \mathrm{O}_{2}$ in the reaction did not greatly affect the product selectivity of benzyl

\section{Table 1}

Oxidation of neat benzyl alcohol using various concentrations of $\mathrm{H}_{2} \mathrm{O}_{2}$.<smiles>[Y]c1ccc(C(=O)O)cc1</smiles>
$\underset{\mathrm{mmol}}{\mathrm{N}_{2}}(1 \mathrm{~atm}=0.1 \mathrm{MPa})$

\begin{tabular}{lcccc}
\hline Entry & $\mathrm{X}$ & $\mathrm{H}_{2} \mathrm{O}_{2}(\mathrm{eq})$ & Conversion to A (\%) & Conversion to B (\%) \\
\hline 1 & $\mathrm{H}$ & 10 & 0 & 100 \\
2 & $\mathrm{H}$ & 2.2 & 0 & 98 \\
3 & $\mathrm{H}$ & 1 & 0 & 63 \\
4 & $\mathrm{H}$ & 0.5 & 0 & 37 \\
5 & $\mathrm{H}$ & 0 & $<5$ & 0 \\
\hline
\end{tabular}

alcohol oxidation, which indicates that only NGO (not $\mathrm{H}_{2} \mathrm{O}_{2}$ ) acts as a catalyst in this reaction (Table 1). Different derivatives of benzyl alcohol exhibited different ratios of aldehyde/carboxylic acid during the oxidation process, and also required different reaction time to reach completion. These results could be attributed to the dependence of the reaction rate on the nature of substituents on the benzyl alcohols, and the rates were in the following order: $-\mathrm{OMe}>-\mathrm{H}>-\mathrm{Cl}>-\mathrm{NO}_{2}$. Because of this dependence, the reaction yield for the oxidation of 4-nitrobenzyl alcohol was low (Table 4). The oxidation results for secondary and primary benzylic alcohols were comparable (Table 5). The highest reaction rate was observed for diphenylmethanol, indicating the role of the substituents groups on the benzylic carbon was in the order $-\mathrm{Ph}>>-\mathrm{H}>$ $-\mathrm{CH}_{3}$.

\subsection{Oxidation of aromatic aldehydes by the NGO carbocatalyst}

In the oxidation of benzaldehyde derivatives, the NGO sheets alone could not act as an oxidant (Table 6) and the reac- 
tion only occurred in the presence of $\mathrm{H}_{2} \mathrm{O}_{2}$. In fact, $\mathrm{H}_{2} \mathrm{O}_{2}$ could induce the reaction even with a low mass fraction of the NGO catalyst (7\%, Tables 7 and 8). The optimum NGO catalyst mass fraction and reaction temperature were $7 \%$ and $70{ }^{\circ} \mathrm{C}$, respec-

Table 2

Oxidation of benzyl alcohol derivatives using NGO catalysts with various concentrations.

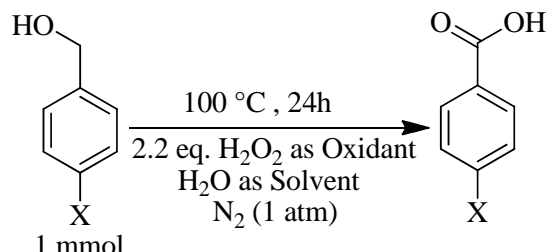

\begin{tabular}{|c|c|c|c|c|c|c|c|c|c|}
\hline \multirow{2}{*}{ Entry } & \multirow{2}{*}{ NGO (\%) } & \multicolumn{2}{|c|}{ 4-Choloro benzyl alcohol } & \multicolumn{2}{|c|}{ 4-Methoxy benzyl alcohol } & \multicolumn{2}{|c|}{ Benzyl alcohol } & \multicolumn{2}{|c|}{ 4-Nitro benzyl alcohol } \\
\hline & & Conversion (\%) & C.W. ${ }^{a}(\mathrm{mg})$ & Conversion (\%) & C.W. ${ }^{\mathrm{a}}(\mathrm{mg})$ & Conversion (\%) & C.W. ${ }^{\text {a }}(\mathrm{mg})$ & Conversion (\%) & C.W. ${ }^{\mathrm{a}}(\mathrm{mg})$ \\
\hline$\overline{1}$ & 200 & 95 & 284 & 99 & 276 & 98 & 210 & 8 & 306 \\
\hline 2 & 100 & 95 & 142 & 99 & 138 & 97 & 105 & 9 & 153 \\
\hline 3 & 50 & 96 & 71 & 99 & 69 & 97 & 52 & 8 & 76 \\
\hline 4 & 30 & 94 & 43 & 99 & 41 & 97 & 32 & 8 & 46 \\
\hline 5 & 20 & 95 & 28 & 99 & 28 & 96 & 21 & 7 & 31 \\
\hline 6 & 10 & 31 & 14 & 63 & 14 & 43 & 10 & $<5$ & 15 \\
\hline 7 & 0 & $<5$ & 0 & $<5$ & 0 & $<5$ & 0 & $<5$ & 0 \\
\hline
\end{tabular}

${ }^{7}$ Catalyst mass (mg).

\section{Table 3}

Oxidation of benzyl alcohol derivatives at various reaction temperatures in the presence of NGO catalysts.

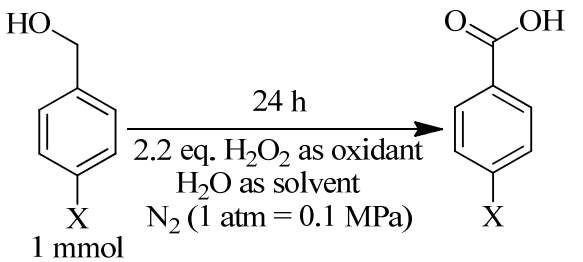

\begin{tabular}{|c|c|c|c|c|c|c|}
\hline Entry & $\begin{array}{c}\text { Temperature } \\
\left({ }^{\circ} \mathrm{C}\right)\end{array}$ & $\begin{array}{c}\text { NGO } \\
\text { (wt } \%)\end{array}$ & $\begin{array}{l}\text { 4-Chloro benzyl alcohol } \\
\text { conversion (\%) }\end{array}$ & $\begin{array}{l}\text { 4-Methoxy benzyl alcohol } \\
\text { conversion (\%) }\end{array}$ & $\begin{array}{c}\text { Benzyl alcohol } \\
\text { conversion (\%) }\end{array}$ & $\begin{array}{l}\text { 4-Nitro benzyl alcohol } \\
\text { conversion (\%) }\end{array}$ \\
\hline 1 & RT & 100 & 0 & 0 & 0 & 0 \\
\hline 2 & 60 & 100 & $<5$ & $<5$ & $<5$ & 0 \\
\hline 3 & 70 & 100 & 31 & 42 & 38 & 0 \\
\hline 4 & 80 & 100 & 94 & 100 & 97 & 8 \\
\hline 5 & 90 & 100 & 95 & 100 & 97 & 8 \\
\hline 6 & 100 & 100 & 95 & 100 & 97 & 9 \\
\hline 7 & RT & 20 & 0 & 0 & 0 & 0 \\
\hline 8 & 60 & 20 & 0 & $<5$ & 0 & 0 \\
\hline 9 & 70 & 20 & 18 & 39 & 38 & 0 \\
\hline 10 & 80 & 20 & 93 & 100 & 96 & 7 \\
\hline 11 & 90 & 20 & 95 & 100 & 97 & 7 \\
\hline 12 & 100 & 20 & 95 & 100 & 97 & 9 \\
\hline
\end{tabular}

Table 4

Oxidation of benzyl alcohol derivatives with various catalytic reaction time in the presence of NGO catalysts.

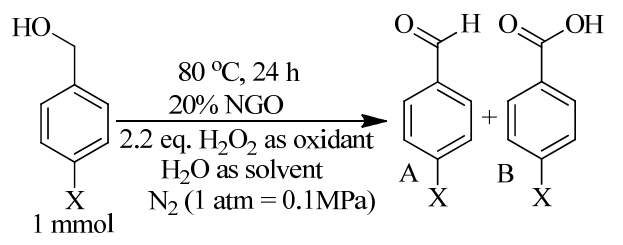

\begin{tabular}{|c|c|c|c|c|c|c|c|c|c|c|c|c|c|c|}
\hline \multirow{3}{*}{ Entry } & \multirow{3}{*}{$\mathrm{X}$} & \multicolumn{12}{|c|}{ Conversion (\%) } & \multirow{3}{*}{$\begin{array}{l}\text { TON } \\
\left(10^{-2}\right)\end{array}$} \\
\hline & & \multicolumn{2}{|c|}{1} & \multicolumn{2}{|c|}{3} & \multicolumn{2}{|c|}{6} & \multicolumn{2}{|c|}{9} & \multicolumn{2}{|c|}{12} & \multicolumn{2}{|c|}{24} & \\
\hline & & $A$ & $B$ & $A$ & $B$ & $\mathrm{~A}$ & $B$ & $A$ & $B$ & $A$ & $B$ & $A$ & $B$ & \\
\hline 1 & $\mathrm{H}$ & 25 & 10 & 19 & 47 & 16 & 73 & 10 & 86 & 0 & 96 & - & - & 4.4 \\
\hline 2 & $\mathrm{OMe}$ & 37 & $<5$ & 40 & 40 & 30 & 70 & 0 & 100 & - & - & - & - & 3.6 \\
\hline 3 & $\mathrm{NO}_{2}$ & 0 & 0 & 0 & 0 & 0 & $<5$ & 0 & 6 & 0 & 8 & 0 & 9 & 0.2 \\
\hline 4 & $\mathrm{Cl}$ & 19 & 11 & 12 & 40 & 10 & 62 & 8 & 72 & $<5$ & 87 & 0 & 93 & 3.3 \\
\hline
\end{tabular}

${ }^{\mathrm{a}}$ The turnover number (TON) was calculated as a ratio of the amount of oxidized product to the mass of NGO. 
Table 5

Oxidation of secondary alcohol derivatives to highlight the role of substrate structure in the oxidation reaction with a NGO catalyst.

\begin{tabular}{|c|c|c|c|c|}
\hline Derivatives & $\begin{array}{c}\text { Catalyst mass } \\
(\mathrm{mg})\end{array}$ & $\begin{array}{l}\text { Time } \\
\text { (h) }\end{array}$ & $\begin{array}{c}\text { Conversion } \\
(\%)\end{array}$ & $\begin{array}{l}\text { TON } \\
\left(10^{-2}\right)\end{array}$ \\
\hline Diphenylmethanol & 52 & 3 & $>99$ & 2.7 \\
\hline 1-Phenylethanol & 24 & 12 & $>99$ & 4.1 \\
\hline
\end{tabular}

${ }^{a}$ The turnover number (TON) was calculated as a ratio of the amount of oxidized product to the mass of NGO.

Table 6

Oxidation of aromatic aldehyde derivatives using $\mathrm{NGO}$ as the catalyst in the absence of $\mathrm{H}_{2} \mathrm{O}_{2}$.

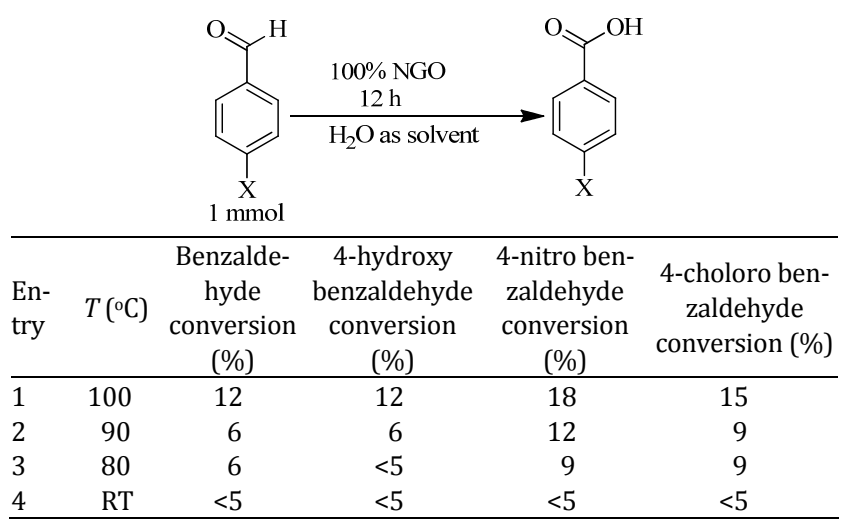

tively, for the oxidation reaction. The reaction time experiments confirmed the dependency of the reaction rate on the substituents. Aldehyde derivatives with electron withdrawing substituents had higher reaction rates than those with other substituents $\left(-\mathrm{NO}_{2}>-\mathrm{Cl}>-\mathrm{H}>-\mathrm{OH}\right)$ (Table 9).

\subsection{Characterization of NGO after oxidation}

The structure of NGO after reaction with $\mathrm{H}_{2} \mathrm{O}_{2}$ at $80{ }^{\circ} \mathrm{C}$ for 8 h (i.e. the optimum conditions for oxidation of benzyl alcohols)
Table 8

Oxidation of aromatic aldehyde derivatives at various reaction temperatures in the presence of NGO catalysts.

\begin{tabular}{|c|c|c|c|c|c|}
\hline & & $\underbrace{\mathrm{X}}_{1 \mathrm{mmol}}$ & $\begin{array}{l}7 \% \mathrm{NGO} \\
12 \mathrm{~h} \\
\text { eq. } \mathrm{H}_{2} \mathrm{O}_{2} \text { as oxida } \\
\mathrm{H}_{2} \mathrm{O} \text { as solvent }\end{array}$ & $X$ & \\
\hline $\begin{array}{l}\text { En- } \\
\text { try }\end{array}$ & $T\left({ }^{\circ} \mathrm{C}\right)$ & $\begin{array}{l}\text { Benzaldehyde } \\
\text { conversion } \\
(\%)\end{array}$ & $\begin{array}{c}\text { 4-Hydroxy } \\
\text { benzaldehyde } \\
\text { conversion } \\
(\%) \\
\end{array}$ & $\begin{array}{c}\text { 4-Nitro ben- } \\
\text { zaldehyde } \\
\text { conversion } \\
(\%)\end{array}$ & $\begin{array}{c}\text { 4-Choloro } \\
\text { benzaldehyde } \\
\text { conversion } \\
(\%)\end{array}$ \\
\hline 1 & RT & 11 & 7 & 14 & 14 \\
\hline 2 & 60 & 27 & 27 & 56 & 33 \\
\hline 3 & 70 & $>99$ & $>99$ & $>99$ & $>99$ \\
\hline 4 & 80 & $>99$ & $>99$ & $>99$ & $>99$ \\
\hline
\end{tabular}

was studied by FTIR and UV-visible spectroscopy. The FTIR spectrum (Fig. 3(c)) showed the characteristic peaks of (e.g. 1062, 1627, and $3428 \mathrm{~cm}^{-1}$ ) and new peaks at 1415 and 3081 $\mathrm{cm}^{-1}$. The NGO peak at $1384 \mathrm{~cm}^{-1}$ shifted to $1415 \mathrm{~cm}^{-1}$ after oxidation, and this peak was similar to that for the $\mathrm{O}-\mathrm{OH}$ bond of peroxy acid [76]. The peak at $3081 \mathrm{~cm}^{-1}$, for the $\mathrm{OH}$ of carboxylic acid, was separated from the $\mathrm{OH}$ peak of phenol, alcohol and adsorbed $\mathrm{H}_{2} \mathrm{O}$, which occurred at $3428 \mathrm{~cm}^{-1}$. The carbonyl peak shifted from $1726 \mathrm{~cm}^{-1}$ for unreacted NGO to $1700 \mathrm{~cm}^{-1}$ for NGO after oxidation, and this peak and the aromatic C-C peak at $1627 \mathrm{~cm}^{-1}$ both increased in intensity. These peaks suggest that oxidation increases the number of carboxylic acid groups in NGO, and converts some of these groups to peroxy acids.

The UV-visible spectrum of the NGO after oxidation (Fig. 3(d)) showed the same absorption peak as unreacted NGO at $224 \mathrm{~nm}$ for the $s p^{2}$ domain of the carbon skeleton $\left(\pi \rightarrow \pi^{*}\right.$ transition of $\mathrm{C}=\mathrm{C}$ bonds). However, the peak for the $\mathrm{n} \rightarrow \pi^{*}$ transition of the $\mathrm{C}=\mathrm{O}$ bonds shifted to $284 \mathrm{~nm}$ for the $\mathrm{NGO}$ after oxidation. This red shift, which was attributed to inter- and intramolecular hydrogen bonding of peroxy acids [77], confirms the formation of peroxy acids from carboxylic acids on the NGO under the oxidation reaction conditions.

Table 7

Oxidation of aromatic aldehyde derivatives using NGO catalysts with various concentrations.

\begin{tabular}{|c|c|c|c|c|c|c|c|c|c|c|c|c|c|}
\hline & & & & & & $\frac{(0 \mathrm{tc}}{1.1 \mathrm{ec}}$ & $\begin{array}{l}\text { C, } 12 \mathrm{~h} \\
\text { \% NG } \\
\mathrm{O}_{2} \text { as ox } \\
\text { s solvent }\end{array}$ & $\mathrm{X}$ & & & & & \\
\hline \multirow{3}{*}{ Entry } & \multirow{3}{*}{$\mathrm{X}$} & \multicolumn{12}{|c|}{ NGO (\%) } \\
\hline & & \multicolumn{2}{|c|}{100} & \multicolumn{2}{|c|}{50} & \multicolumn{2}{|c|}{20} & \multicolumn{2}{|c|}{7} & \multicolumn{2}{|c|}{5} & \multicolumn{2}{|c|}{0} \\
\hline & & $\begin{array}{l}\text { Con. } \\
(\%)\end{array}$ & $\begin{array}{l}\text { C.W. }^{\mathrm{a}} \\
\text { (mg) }\end{array}$ & $\begin{array}{l}\text { Con. } \\
(\%)\end{array}$ & $\begin{array}{l}\text { C.W. }^{a} \\
\text { (mg) }\end{array}$ & $\begin{array}{l}\text { Con. } \\
(\%)\end{array}$ & $\begin{array}{l}\text { C.W. }^{\mathrm{a}} \\
\text { (mg) }\end{array}$ & $\begin{array}{l}\text { Con. } \\
(\%)\end{array}$ & $\begin{array}{l}\text { C.W. }^{\text {a }} \\
\text { (mg) }\end{array}$ & $\begin{array}{l}\text { Con. } \\
(\%)\end{array}$ & $\begin{array}{l}\text { C.W. }^{\text {a }} \\
\text { (mg) }\end{array}$ & $\begin{array}{l}\text { Con. } \\
(\%)\end{array}$ & $\begin{array}{l}\text { C.W. }^{a} \\
(\mathrm{mg})\end{array}$ \\
\hline 1 & $\mathrm{H}$ & $>99$ & 106 & $>99$ & 53 & $>99$ & 21 & $>99$ & 8 & 46 & 5 & 18 & 0 \\
\hline 2 & $\mathrm{OH}$ & $>99$ & 122 & $>99$ & 61 & $>99$ & 24 & $>99$ & 9 & 38 & 6 & $<5$ & 0 \\
\hline 3 & $\mathrm{NO}_{2}$ & $>99$ & 151 & $>99$ & 76 & $>99$ & 30 & $>99$ & 11 & 63 & 8 & 32 & 0 \\
\hline 4 & $\mathrm{Cl}$ & $>99$ & 140 & $>99$ & 70 & $>99$ & 28 & $>99$ & 10 & 48 & 7 & 16 & 0 \\
\hline
\end{tabular}

${ }^{\mathrm{a}}$ Catalyst mass (mg). 


\section{Table 9}

The catalytic reaction time required for oxidation of aromatic aldehyde to yield a conversion rate of $>99 \%$.<smiles>[X]c1ccc(C(=O)O)cc1C(=O)O[Na]</smiles>

\begin{tabular}{lccccc}
\hline $\begin{array}{l}\text { En- } \\
\text { try }\end{array}$ & Derivatives & $\begin{array}{c}\text { Benzal- } \\
\text { dehyde }\end{array}$ & $\begin{array}{c}\text { 4-Hydroxy } \\
\text { benzalde- } \\
\text { hyde }\end{array}$ & $\begin{array}{c}\text { 4-Nitro } \\
\text { benzalde- } \\
\text { hyde }\end{array}$ & $\begin{array}{c}\text { 4-Choloro } \\
\text { benzalde- } \\
\text { hyde }\end{array}$ \\
\hline 1 & Time (min) & 150 & 180 & 120 & 132 \\
2 & Conversion $(\%)$ & $>99$ & $>99$ & $>99$ & $>99$ \\
3 & TON $^{\text {a }}\left(10^{-2}\right)$ & 13.5 & 11.7 & 9.5 & 10.2 \\
\hline
\end{tabular}

${ }^{a}$ The turnover number (TON) was calculated as a ratio of the amount of oxidized product to the mass of NGO.

\subsection{Oxidation using similar catalysts}

The oxidation of benzyl alcohols and benzaldehydes was investigated using NGO-amide and acetic acid as catalysts to study the effect of the acidic nature of NGO (Scheme 1(b) and (c)), benzoic acid to study the autocatalytic effect of the reaction product (Scheme 1(d)), and epoxy cyclohexane to study the role of epoxide groups in NGO (Scheme 1(e)). The reaction did not proceed using these catalysts. This means that no autocatalytic effect occurred during the oxidation reaction. It also indicates that although the acidic nature of NGO is important in the oxidation reaction, this property alone cannot catalyze the reaction. In fact, the high performance of NGO as a catalyst in the reactions can be assigned to the synergistic effects of its surface functional groups (not the active sites separately). It should be noted that the oxidation of benzyl alcohols by mCPBA resulted in production of benzaldehyde and benzoic acid, and the selectivity was comparable to the NGO catalyst (Scheme 1(f)). There was no conversion of benzyl alcohols in the presence of KI, even under the optimum conditions, indicating that radical interactions were important in the NGO catalysis (Scheme 1(g)).
Catalysis with NGO occurs in two major steps, activation of the catalyst by the oxidant, and then oxidation of the substrate by the activated catalyst. In the activation step, the peroxidase-like ability of NGO leads to activation by the oxidant, and NGO is converted to the active catalyst through radical interactions. This was confirmed by results obtained for oxidation of benzyl alcohol in the presence of KI. Based on the FTIR and UV-visible spectroscopy results for NGO after oxidation, the similar product selectivity for benzyl alcohol oxidation by mCPBA and NGO separately, and the oxidation of alcohol and/or aldehyde by NGO-amide, we believe the activated catalyst is NGO-peroxy acid. This activated catalyst is formed through oxidation of the carboxylic group of NGO to peroxy acid. In the subsequent catalytic cycle, the activated catalyst (NGO-peroxy acid) acts as an oxidant in oxidation of the substrate through a non-radical interaction, which was confirmed by the dramatic difference between the yield of oxidation of 4-nitrobenzyl alcohol and other alcohol derivatives. The order of the oxidation rates of diphenylmethanol, benzyl alcohol, and 1-phenylethanol also confirmed this interaction did not involve radicals because these results are incompatible with radical reactions [78]. These steps are also in accordance with previous reports on GO [30]. Therefore, based on what the above descriptions, we proposed mechanisms for activation of the NGO, oxidation of alcohol to aldehyde, and oxidation of aldehyde to carboxylic acid.

\subsection{Activation mechanism of NGO}

According to our proposed mechanism for activation of NGO (Scheme 2), lone pair electrons delocalized at the vacancies at the edges of the zigzag structure of the conjugated $\pi$-system activate the oxygen group of $\mathrm{H}_{2} \mathrm{O}_{2}$. Then, activated oxygen, through a series of radical interactions with the carboxylic acid groups of NGO, leads to formation of NGO-peroxy acid as the activated catalyst. This is compatible with the traditional synthesis for peoxy acid by $\mathrm{H}_{2} \mathrm{O}_{2}$ in an acidic medium [79].

\subsection{Mechanism for oxidation of alcohols to aldehydes}

Based on our proposed mechanism for oxidation of alcohol

\section{Discussion}

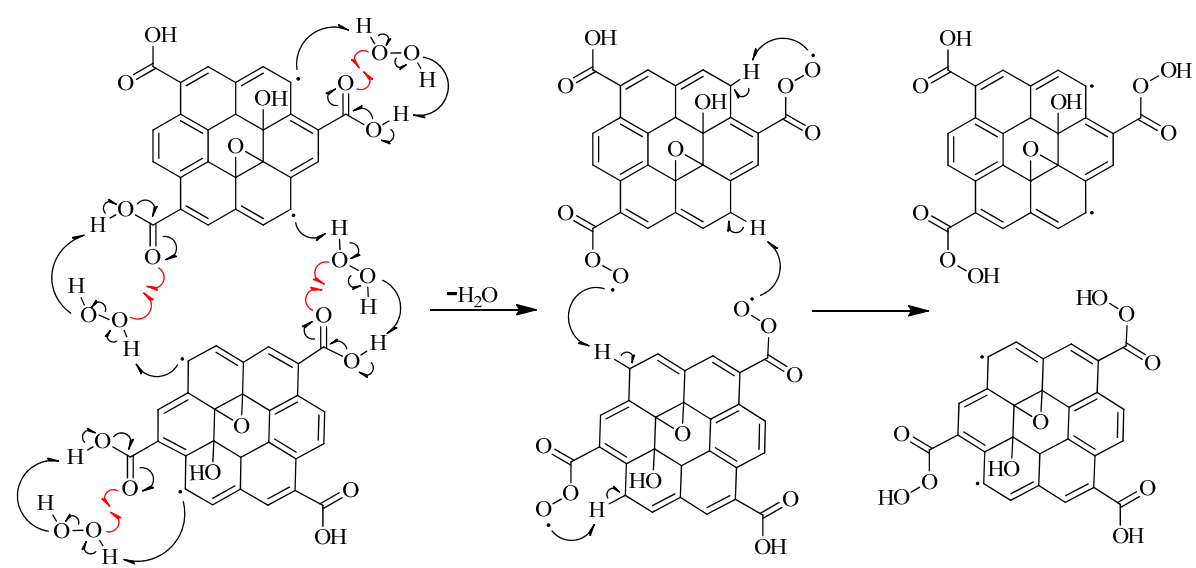

Scheme 2. The activation mechanism of the NGO catalyst. 
to aldehyde (Scheme 3), after activation of NGO to NGO-peroxy acid, with protonation of the hydroxyl group of the alcohol by peroxy acid of NGO, partial positive charge formation can occur at the benzylic carbon. Then, nucleophilic attack by oxygen from the peroxy acid to the benzylic position occurs with loss of $\mathrm{H}_{2} \mathrm{O}$, and this leads to formation of structure A as an intermediate. A C-H bond at the benzylic carbon and $\mathrm{O}-\mathrm{O}$ bond in intermediate A then break and reforms NGO-carboxylic acid and the aldehyde product. The catalytic cycle can then continue. Intermediate $\mathrm{A}$, and its decomposition process, are consistent with a Criegee intermediate, and the higher migration ability of $H$ to the aryl group of this intermediate in the Baeyer-Villiger reaction with mCPBA as oxidant $[80,81]$. The dependence of the reaction rate and yield for oxidation of secondary alcohols on the substituents at the benzylic carbon, and that of primary alcohols on the substituents on the aromatic ring, determined the formation of a partial positive charge at benzylic carbon, and its stability is rate-limiting. 4-Nitrobenzyl alcohol, which has the strongest electron withdrawing substituent, has the lowest density of electrons at the benzylic carbon and the lowest ability for formation of a positive charge at this site, which results in the lowest reaction rate and yields among the alcohol derivatives. Among the alcohols, diphenylmethanol, which has two electron donating substituents, has the highest electron density at this position and the highest ability to form a positive charge at this site. Consequently, it had the highest reaction rate and yield for the oxidation among the alcohol derivatives.

\subsection{Mechanism of oxidation of aldehydes to carboxylic acids}

In accordance with our proposed mechanism for oxidation of aldehydes to carboxylic acids (Scheme 4), protonation of the oxygen group of the carbonyl and immediate nucleophilic attack to the carbon of carbonyl groups by peroxy acid of NGO leads to formation of structure $\mathrm{B}$ as an intermediate. Then, loss of benzylic $\mathrm{C}-\mathrm{H}$ and $\mathrm{O}-\mathrm{O}$ bonds in intermediate $\mathrm{B}$ results in formation of NGO-carboxylic acid and the carboxylic acid product. All aspects of this mechanism, such as the order of steps and the structure of $\mathrm{B}$, are consistent with the mechanism of Baeyer-Villiger reaction with mCPBA as the oxidant $[80,81]$. Based on the results for oxidation of aldehydes, it is clear that as with the alcohol oxidation, the density of electrons at the

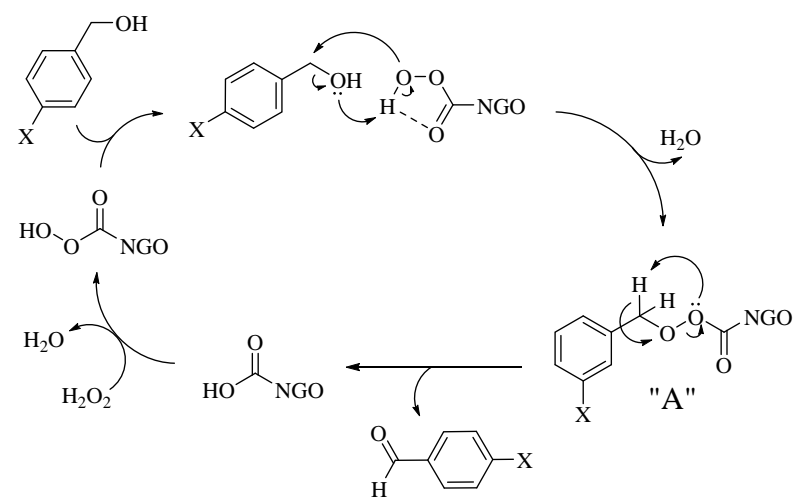

Scheme 3. The oxidation mechanism for conversion of benzyl alcohols to aromatic aldehydes using the NGO catalyst.

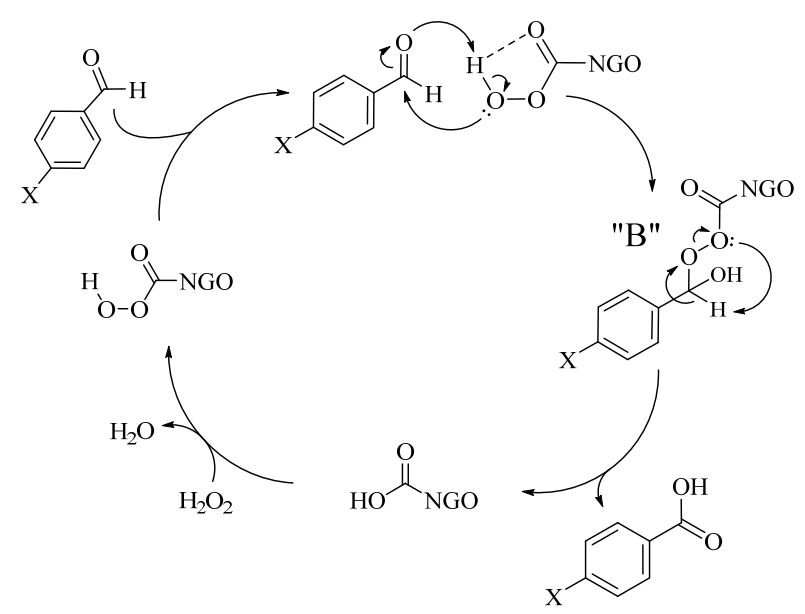

Scheme 4. The oxidation mechanism for conversion of aromatic aldehydes to carboxylic acids using the NGO catalyst.

benzylic carbon plays an important role. In contrast with the alcohols, aldehyde derivatives with stronger electron withdrawing substituents on the aromatic ring have higher reaction rates for the oxidation. In summary, the dependency of the oxidation reaction rates and yields for the alcohols and aldehydes on the substrate substituents, and the general principles of these mechanisms, are similar to to the oxidation of ketones by $\mathrm{mCPBA}$ in the Baeyer-Villiger reaction.

\subsection{Comparison of NGO carbocatalysts with other graphene-based carbocatalysts for oxidation}

Compared with the protocols for GO, rGO, nitrogen-doped graphene, and nitrogen-doped activated carbon, the NGO protocol is greener with a shorter reaction time, lower temperature, and lower carbocatalyst requirements. The results confirmed that reduction of the size of GO was effective for increasing the catalytic performance. Compared with GO, the NGO carbocatalytic reaction uses a lower temperature, shorter reaction time, less carbocatalyst, and has a higher conversion yield for some substrates (e.g. 1-phenylethanol, Table 10, entries 1-3). In addition, the oxidation of alcohols has different selectivity in some cases (e.g. benzyl alcohol, Table 10, entries 9-11). Compared with $\mathrm{N}$-doped graphene, NGO is very similar and gives the same selectivity and conversion yield, but NGO is considered a greener oxidant with a lower carbocatalytic load (Table 10, entries 4, 5, 9 and 10). Nitrogen-doped activated carbon carbocatalysts have been studied for the oxidation of benzyl alcohol over $5 \mathrm{~h}$ using $\mathrm{O}_{2}$ as the oxidant. However, the reaction has a low yield and requires a higher temperature and higher load of carbocatalyst than if the reaction is conducted with NGO (Table 10, entries 6 and 9). The rGO does not act as a catalyst in the oxidation of benzylic alcohols [82] (Table 10, entries 7 and 8).

\section{Conclusions}

In this study, the catalytic activity of GO was increased by reduced the size of GO sheets to NGO. The NGO is a green oxi- 
Table 10

Comparison of NGO carbocatalysts with other graphene-based carbocatalysts.

\begin{tabular}{|c|c|c|c|c|c|c|c|c|c|}
\hline Entry & Substrate & Catalyst & Load of catalyst & Oxidant & $T\left({ }^{\circ} \mathrm{C}\right)$ & $t(\mathrm{~h})$ & Conversion yield (\%) & Product & Ref. \\
\hline 1 & & GO & $200 \%$ & $\mathrm{O}_{2} / \mathrm{GO}$ & 100 & 24 & 92 & & {$[30]$} \\
\hline 2 & & GO & $200 \%$ & $\mathrm{O}_{2} / \mathrm{GO}$ & 100 & 24 & 98 & & {$[30]$} \\
\hline 3 & & GO & $200 \%$ & $\mathrm{O}_{2} / \mathrm{GO}$ & 100 & 24 & 26 & & {$[30]$} \\
\hline 4 & & $\begin{array}{l}\text { N-doped } \\
\text { graphene }\end{array}$ & $55 \%$ (30 mg) & TBHP & 80 & 12 & 99 & & {$[47]$} \\
\hline 5 & & $\begin{array}{l}\mathrm{N} \text {-doped } \\
\text { graphene }\end{array}$ & $50 \%(30 \mathrm{mg})$ & TBHP & 80 & 12 & 99 & & {$[47]$} \\
\hline 6 & & $\begin{array}{c}\mathrm{N} \text {-doped } \\
\text { activated carbon }\end{array}$ & 85\% (100 mg) & $\mathrm{O}_{2}$ & 120 & 5 & 23 & & {$[48]$} \\
\hline 7 & & rGO & $18 \%$ (6 mg) & $\mathrm{O}_{2}$ & 100 & 12 & 0 & & {$[82]$} \\
\hline 8 & & rGO & $16 \%$ (6 mg) & $\mathrm{O}_{2}$ & 100 & 12 & 0 & - & {$[82]$} \\
\hline 9 & & NGO & $20 \%$ (21 mg) & $\mathrm{H}_{2} \mathrm{O}_{2}$ & 80 & 12 & 96 & & $\begin{array}{l}\text { This } \\
\text { work }\end{array}$ \\
\hline 10 & & NGO & $20 \%(24 \mathrm{mg})$ & $\mathrm{H}_{2} \mathrm{O}_{2}$ & 80 & 12 & 99 & & $\begin{array}{l}\text { This } \\
\text { work }\end{array}$ \\
\hline 11 & & NGO & $20 \%$ (52mg) & $\mathrm{H}_{2} \mathrm{O}_{2}$ & 80 & 3 & 99 & & $\begin{array}{l}\text { This } \\
\text { work }\end{array}$ \\
\hline
\end{tabular}

dant for the conversion of benzyl alcohols and aromatic aldehydes in the presence of $\mathrm{H}_{2} \mathrm{O}_{2}$ in aqueous media at low temperatures $\left(70-80^{\circ} \mathrm{C}\right)$. The catalytic efficiency of the NGO colloidal dispersion is comparable with those of conventional metal-based catalysts. The performance of this carbocatalyst is dependent on a number of reaction conditions because the catalytic cycle of NGO involves radicals in catalyst activation but not in substrate oxidation. Overall, NGO is a powerful and environmental-friendly (metal-free) catalyst for oxidation of some benzyl alcohols, depending on the nature of the substituents, and all aromatic aldehydes (substituent-independent). NGO is promising for applications in environmental chemistry.

\section{References}

[1] H. W. Hu, J. H. Xin, H. Hu, X. W. Wang, Y. Y. Kong, Appl. Catal. A, 2015, 492, 1-9.

[2] S. L. Y. Tang, R. L. Smith, M. Poliakoff, Green Chem., 2005, 7, 761-762.

[3] I. T. Horvath, P. T. Anastas, Chem. Rev., 2007, 107, 2169-2173.

[4] O. Akhavan, M. Choobtashani, E. Ghaderi, J. Phys. Chem. C, 2012, $116,9653-9659$.
[5] O. Akhavan, E. Ghaderi, J. Phys. Chem. C, 2009, 113, 20214-20220.

[6] Z. Y. Wang, Y. Huang, W. K. Ho, J. J. Cao, Z. X. Shen, S. C. Lee, Appl. Catal. B, 2016, 199, 123-133.

[7] Y. Huang, W. Wang, Q. Zhang, J. J. Cao, R. J. Huang, W. K. Ho, S. C. Lee, Sci. Rep., 2016, 6, 23435.

[8] Q. Zhang, Y. Huang, L. F. Xu, J. J. Cao, W. K. Ho, S. C. Lee, ACS Appl. Mater. Interfaces, 2016, 8, 4165-4174.

[9] O. Akhavan, J. Colloid Interface Sci., 2009, 336, 117-124.

[10] O. Akhavan, M. Abdolahad, Y. Abdi, S. Mohajerzadeh, Carbon, 2009, 47, 3280-3287.

[11] J. C. Védrine, Appl. Catal. A, 2014, 474, 40-50.

[12] Q. Q. Zhuo, Y. Y. Ma, J. Gao, P. P. Zhang, Y. J. Xia, Y. M. Tian, X. X. Sun, J. Zhong, X. H. Sun, Inorg. Chem., 2013, 52, 3141-3147.

[13] J. Pyun, Angew. Chem. Int. Ed., 2011, 50, 46-48.

[14] J. Zhang, X. Liu, R. Blume, A. H. Zhang, R. Schlögl, D. S. Su, Science, 2008, 322, 73-77.

[15] Y. Wang, X. C. Wang, M. Antonietti, Angew. Chem. Int. Ed., 2012, 51, 68-89.

[16] C. L. Su, K. P. Loh, Acc. Chem. Res., 2013, 46, 2275-2285.

[17] Z. K. Zhao, G. F. Ge, W. Z. Li, X. W. Guo, G. R. Wang, Chin. J. Catal., 2016, 37, 644-670.

[18] S. Navalon, A. Dhakshinamoorthy, M. Alvaro, H. Garcia, Chem. Rev., 2014, 114, 6179-6212. 


\section{Graphical Abstract}

Chin. J. Catal., 2017, 38: 745-757 doi: 10.1016/S1872-2067(17)62776-1

Nanoscale graphene oxide sheets as highly efficient carbocatalysts in green oxidation of benzylic alcohols and aromatic aldehydes

Alireza Sedrpoushan*, Masoud Heidari, Omid Akhavan

Iranian Research Organization for Science and Technology (IROST); Sharif University of Technology

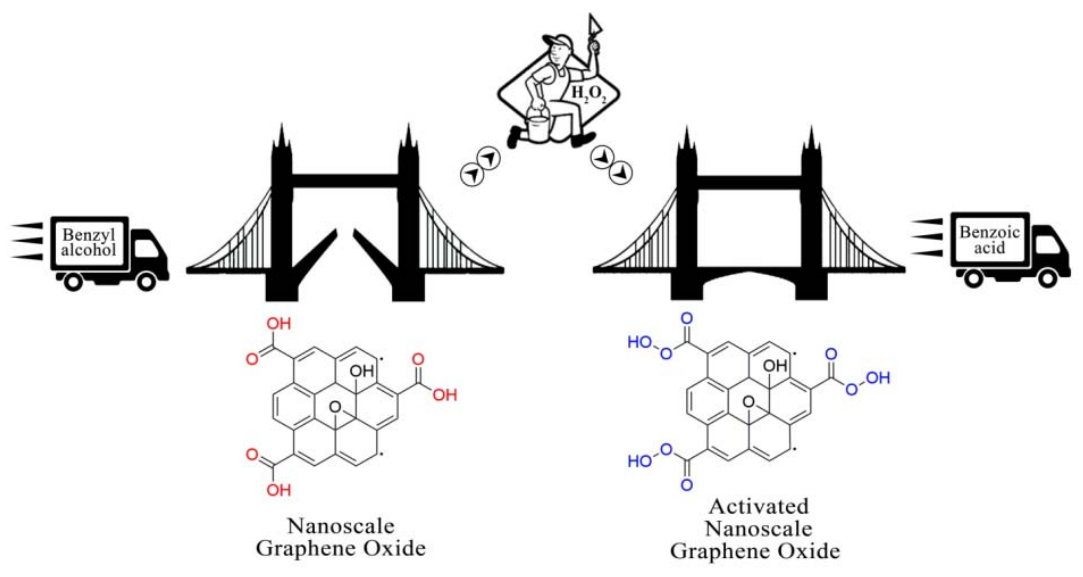

Nanoscale graphene oxide sheets as active graphene-based carbocatalysts with peroxidase-like activity convert to peroxybenzoic acid in the presence of $\mathrm{H}_{2} \mathrm{O}_{2}$, and act as efficient catalysts for oxidation of benzylic alcohols.

[19] M. S. Dresselhaus, ACS Nano, 2010, 4, 4344-4349.

[20] M. Prato, J. Mater. Chem., 1997, 7, 1097-1109.

[21] B. J. Li, Z. Xu, J. Am. Chem. Soc., 2009, 131, 16380-16382.

[22] B. Frank, R. Blume, A. Rinaldi, A. Trunschke, R. Schlögl, Angew. Chem. Int. Ed., 2011, 50, 10226-10230.

[23] D. S. Su, N. Maksimova, J. J. Delgado, N. Keller, G. Mestl, M. J. Ledoux, R. Schlögl, Catal. Today, 2005, 102-103, 110-114.

[24] M. F. R. Pereira, J. J. M. Orfao, J. L. Figueiredo, Appl. Catal. A, 2001, 218, 307-318.

[25] B. F. Machado, P. Serp, Catal. Sci. Technol., 2012, 2, 54-75.

[26] J. Y. Diao, H. Y. Liu, Z. B. Feng, Y. J. Zhang, T. Chen, C. X. Miao, W. M. Yang, D. S. Su, Catal. Sci. Technol., 2015, 5, 4950-4953.

[27] D. R. Dreyer, C. W. Bielawski, Chem. Sci., 2011, 2, 1233-1240.

[28] N. Kausar, P. Mukherjee, A. R. Das, RSC Adv., 2016, 6, 88904-88910.

[29] N. Kausar, I. Roy, D. Chattopadhyay, A. R. Das, RSC $A d v,$. 2016, 6, 22320-22330.

[30] L. R. Radovic, C. Mora-Vilches, A. J. A. Salgado-Casanova, Chin. J. Catal., 2014, 35, 792-797.

[31] S. Verma, H. P. Mungse, N. Kumar, S. Choudhary, S. L. Jain, B. Sain, O. P. Khatri, Chem. Commun., 2011, 47, 12673-12675.

[32] M. R. Acocella, M. Mauro, G. Guerra, ChemSusChem, 2014, 7, 3279-3283.

[33] A. Sengupta, C. L. Su, C. L. Bao, C. T. Nai, K. P. Loh, ChemCatChem, 2014, 6, 2507-2511.

[34] A. Vijay Kumar, K. Rama Rao, Tetrahedron Lett., 2011, 52, 5188-5191.

[35] F. J. Liu, J. Sun, L. F. Zhu, X. J. Meng, C. Z. Qi, F. S. Xiao, J. Mater. Chem., 2012, 22, 5495-5502.

[36] J. Y. Ji, G. H. Zhang, H. Y. Chen, S. L. Wang, G. L. Zhang, F. B. Zhang, X. B. Fan, Chem. Sci., 2011, 2, 484-487.

[37] D. R. Dreyer, K. A. Jarvis, P. J. Ferreira, C. W. Bielawski, Polym. Chem., 2012, 3, 757-766.
[38] L. Tan, B. Wang, H. X. Feng, RSC Adv., 2013, 3, 2561-2565.

[39] D. R. Dreyer, H. P. Jia, C. W. Bielawski, Angew. Chem. Int. Ed., 2010, 49, 6813-6816.

[40] X. K. Kong, Q. W. Chen, Z. Y. Lun, J. Mater. Chem. A, 2014, 2, 610-613.

[41] X. Zhang, X. Ji, R. F. Su, B. L. Weeks, Z. Zhang, S. L. Deng, ChemPlusChem, 2013, 78, 703-711.

[42] J. H. Yang, G. Sun, Y. J. Gao, H. B. Zhao, P. Tang, J. Tan, A H. Lu, D. Ma, Energy Environ. Sci., 2013, 6, 793-798.

[43] D. H. Long, W. Li, L. C. Ling, J. Miyawaki, I. Mochida, S. H. Yoon, Langmuir, 2010, 26, 16096-16102.

[44] C. N. R. Rao, A. K. Sood, K. S. Subrahmanyam, A. Govindaraj, Angew. Chem. Int. Ed., 2009, 48, 7752-7777.

[45] C. D. Weber, C. Bradley, M. C. Lonergan, M. M. Li, F. Xu, H. R. Li, Y. Wang, Catal. Sci. Technol., 2016, 6, 3670-3693.

[46] J. L. Long, X. Q. Xie, J. Xu, Q. Gu, L. M. Chen, X. X. Wang, ACS Catal., 2012, 2, 622-631.

[47] A. K. Singh, K. C. Basavaraju, S. Sharma, S. Jang, C. P. Park, D. P. Kim, Green Chem., 2014, 16, 3024-3030.

[48] H. Watanabe, S. Asano, S. I. Fujita, H. Yoshida, M. Arai, ACS Catal., 2015, 5, 2886-2894.

[49] A. Dhakshinamoorthy, A. Primo, P. Concepcion, M. Alvaro, H. Garcia, Chem. Eur. J., 2013, 19, 7547-7554.

[50] X. H. Li, M. Antonietti, Angew. Chem. Int. Ed., 2013, 52, 4572-4576.

[51] Y. J. Gao, G. Hu, J. Zhong, Z. J. Shi, Y. S. Zhu, D. S. Su, J. G. Wang, X. H. Bao, D. Ma, Angew. Chem. Int. Ed., 2013, 52, 2109-2113.

[52] Z. B. Wang, X. C. Lü, J. Weng, Carbon, 2013, 62, 51-60.

[53] R. S. Ribeiro, A. M. T. Silva, J. L. Figueiredo, J. L. Faria, H. T. Gomes, Carbon, 2013, 62, 97-108.

[54] H. J. Sun, N. Gao, K. Dong, J. S. Ren, X. G. Qu, ACS Nano, 2014, 8, 6202-6210.

[55] X. L. Hou, J. L. Li, S. C. Drew, B. Tang, L. Sun, X. G. Wang, J. Phys. 
Chem. C, 2013, 117, 6788-6793.

[56] O. Ivanciuc, D. J. Klein, L. Bytautas, Carbon, 2002, 40, 2063-2083.

[57] R. C. Feng, W. Zhou, G. H. Guan, C. C. Li, D. Zhang, Y. N. Xiao, L. C. Zheng, W. X. Zhu, J. Mater. Chem., 2012, 22, 3982-3989.

[58] L. Peng, Y. C. Zheng, J. C. Li, Y. Jin, C. Gao, ACS Catal., 2015, 5, 3387-3392.

[59] G. Gonçalves, M. Vila, I. Bdikin, A. de Andrés, N. Emami, R. A. S. Ferreira, L. D. Carlos, J. Grácio, P. A. A. P. Marques, Sci. Rep., 2014, 4, 6735 .

[60] F. Yang, M. L. Zhao, B. Z. Zheng, D. Xiao, L. Wu, Y. Guo, J. Mater. Chem., 2012, 22, 25471-25479.

[61] W. S. Hummers Jr., R. E. Offeman, J. Am. Chem. Soc., 1958, 80, 1339-1339.

[62] E. Hashemi, O. Akhavan, M. Shamsara, S. Valimehr, R. Rahighi, RSC Adv., 2014, 4, 60720-60728.

[63] L. M. Dai, Acc. Chem. Res., 2013, 46, 31-42.

[64] J. M. Monteagudo, A. Duran, I. San Martin, A. Carnicer, Appl. Catal. $B, \mathbf{2 0 1 1}, 106,242-249$.

[65] H. C. Schniepp, J. L. Li, M. J. McAllister, H. Sai, M. Herrera-Alonson, D. H. Adamson, R. K. Prud'homme, R. Car, D. A. Seville, I. A. Aksay, J. Phys. Chem. B, 2006, 110, 8535-8539.

[66] M. J. McAllister, J. L. Li, D. H. Adamson, H. C. Schniepp, A. A. Abdala, J. Liu, M. Herrera-Alonso, D. L. Milius, R. Car, R. K. Prud'homme, I. A. Aksay, Chem. Mater., 2007, 19, 4396-4404.

[67] O. Akhavan, Carbon, 2010, 48, 509-519.

[68] L. L. Li, G. H. Wu, G. H. Yang, J. Peng, J. W. Zhao, J. J. Zhu, Nanoscale, 2013, 5, 4015-4039.
[69] A. C. Ferrari, J. Robertson, Phys. Rev. B, 2000, 61, 14095-14107.

[70] S. Stankovich, D. A. Dikin, R. D. Piner, K. A. Kohlhaas, A. Kleinhammes, Y. Y. Jia, Y. Wu, S. T. Nguyen, R. S. Ruoff, Carbon, 2007, 45, 1558-1565.

[71] A. C. Ferrari, J. C. Meyer, V. Scardaci, C. Casiraghi, M. Lazzeri, F. Mauri, S. Piscanec, D. Jiang, K. S. Novoselov, S. Roth, A. K. Geim, Phys. Rev. Lett., 2006, 97, 187401/1-187401/4.

[72] E. E. Ghadim, N. Rashidi, S. Kimiagar, O. Akhavan, F. Manouchehri, E. Ghaderi, Appl. Surf. Sci., 2014, 301, 183-188.

[73] R. J. Li, X. Q. Liu, X. L. Deng, S. R. Zhang, Q. He, X. J. Chang, Mater. Lett. 2012, 76, 247-249.

[74] Y. Liu, C. Y. Liu, Y. Liu, Appl. Surf. Sci, 2011, 257, 5513-5518.

[75] S. Kim, S. W. Hwang, M. K. Kim, D. Y. Shin, D. H. Shin, C. O. Kim, S. B. Yang, J. H. Park, E. Hwang, S. H. Choi, G. Ko, S. Sim, C. Sone, H. J. Choi, S. Bae, B. H. Houg, ACS Nano, 2012, 6, 8203-8208.

[76] J. Cugley R. Meyer, H. H. Günthard, Chem. Phys., 1976, 18, 281-292.

[77] D. Swern, L. P. Witnauer, C. R. Eddy, W. E. Parker, J. Am. Chem. Soc., 1955, 77, 5537-5541.

[78] M. B. Smith, J. March, March's Advanced Organic Chemistry: Reactions, Mechanisms, and Structure, 5th Ed., John Wiley \& Sons, 2001.

[79] S. Pohjanvesi, E. L. Mustonen, A. Pukkinen, R. Lehtinen, 2004.

[80] M. Renz, B. Meunier, Eur.J. Org. Chem., 1999, 1999, 737-750.

[81] R. Bruckner, M. Harmata, P. A. Wender, Org. Mech. React. Stereochem. Synth., 2010, 1-855.

[82] S. Sabater, J. A. Mata, E. Peris, ACS Catal,. 2014, 4, 2038-2047.

\title{
纳米尺度氧化石墨烯层作为高效碳催化剂用于苄醇与芳香醛的绿色氧化
}

\author{
Alireza Sedrpoushan ${ }^{\text {a, }}$, Masoud Heidari ${ }^{\text {a }}$, Omid Akhavan ${ }^{\text {b,c }}$ \\ a伊朗科学技术研究组织化工技术系, 德黑兰33535-111, 伊朗

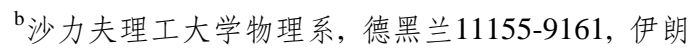 \\ c 沙力夫理工大学纳米科学与纳米技术研究所, 德黑兰14588-89694, 伊朗
}

\begin{abstract}
摘要: 合成了纳米尺度氧化石墨烯(NGO)层, 用作碳催化剂高效催化苄醇与芳香醛的氧化反应. 对于醇氧化反应, 当 $80{ }^{\circ} \mathrm{C}$ 时 $\mathrm{H}_{2} \mathrm{O}_{2}$ 存在下, NGOs (20 wt\%)可高效催化醇选择性生成醛, 其反应速率和产率取决于醇上取代基的性质. 对于4-硝基苄 醇, 反应 $24 \mathrm{~h}$ 后, 只有 $10 \%$ 可转换为相应羒酸. 相反, 4-甲氧基苄醇和二苯基甲醇分别反应仅 9 和 $3 \mathrm{~h}$ 则可完全转化为对应的 羧酸和酮. NGO碳催化剂上芳香酫氧化速率高于醇氧化速率. 对于所有的酫, 采用 $7 \mathrm{wt} \% \mathrm{NGO}$ 作催化剂, 在 $70{ }^{\circ} \mathrm{C} 反$ 应 $2-3 \mathrm{~h}$ 后, 就可完全转化为相应羒酸. 我们讨论了NGO催化剂结构对苄醇和芳香醛氧化反应影响的可能机理.
\end{abstract}

关键词: 碳催化剂; 纳米尺度氧化石墨烯; 绿色化学; 氧化; 无金属催化剂; 胶体分散

收稿日期: 2016-11-19. 接受日期: 2016-12-22. 出版日期: 2017-04-05.

*通讯联系人. 电子信箱: sedrpoushan1395@gmail.com

本文的英文电子版由Elsevier出版社在ScienceDirect上出版(http://www.sciencedirect.com/science/journal/18722067). 